\title{
Considerações sobre as mudanças no registro dos transportadores rodoviários remunerados de carga no Brasil
}

\author{
Pedro Coimbra Machado Valente Cibulska ${ }^{1}$, Giovanna Megumi Ishida Tedesco ${ }^{2}$, \\ Thais Maria de Andrade Villela ${ }^{3}$ e Sérgio Ronaldo Granemann ${ }^{4}$
}

\begin{abstract}
Resumo: Este artigo avalia as possíveis mudanças no mercado de transporte rodoviário remunerado de cargas em consequência da regulação do setor pela Agência Nacional de Transportes Terrestres (ANTT). O embasamento jurídico para a introdução de novos marcos regulatórios está na publicação da Lei $n^{\circ}$. 11.442/07 e da Resolução ANTT nº. 3.056/09. Assim, serão analisadas as exigências para a entrada de novos transportadores rodoviários remunerados de carga no mercado e para a permanência de transportadores que já atuavam no setor. À luz dessa nova legislação, serão avaliadas as exigências relativas à atividade principal do transportador, à responsabilidade técnica comprovada por meio de cursos ou da experiência do transportador, à idoneidade, à regularidade fiscal e cadastral, entre outros aspectos inseridos pela legislação. Pode-se concluir que o advento da nova legislação modificou as práticas regulatórias e a estrutura do setor.
\end{abstract}

Palavras-chave:

Abstract: This article evaluates the possible changes in the road freight transportation market as a result of sector regulation by the Brazilian Agency for Land Transportation (ANTT). The legal basis for those new regulatory frameworks are the publication of Law $\mathrm{n}$. 11.442/07 and Resolution ANTT n. 3.056/09. Thus, this work analyzes the requirements for the entry of new carriers on road freight transportation market and to the permanence of carriers that are already operating in the sector. It can be concluded that the advent of new legislation changed the regulatory practices and industry structure.

Keywords:.

\section{INTRODUÇÃO}

A implantação do Registro Nacional de Transportadores Rodoviários de Cargas no Brasil (RNTRC), no ano de 2004, pela Agência Nacional de Transportes Terrestres (ANTT), pode ser considerado um marco regulatório importante por parte do poder público brasileiro.

De acordo com a Lei $n^{\circ}$. 10.233, que criou a ANTT (Brasil, 2001), e a Resolução nº 01 (ANTT, 2002) e suas alterações, compete à ANTT efetuar o registro e também promover estudos e levantamentos relativos à frota de caminhões, às empresas constituídas e aos operadores autônomos do setor. Dessa forma, a partir de 2004, com a publicação da Resolução n ${ }^{\circ} .437$ (ANTT, 2004), a ANTT passou a organizar e manter atualizado o RNTRC, ou seja, o banco de dados com o cadastro dos transportadores rodoviários de cargas. Tal registro começou a se consolidar como uma ferramenta de apoio para o conhecimento do mercado, criando condições para as funções de regulação e fiscalização setorial da Agência.

Segundo a ANTT (2009b), os principais benefícios do RNTRC são:

\footnotetext{
${ }^{1}$ Pedro Coimbra Machado Valente Cibulska, Centro Interdisciplinar de Estudos em Transportes, Universidade de Brasília, Brasília, DF, Brasil. (e-mail: cibulska@gmail.com).

${ }^{2}$ Giovanna Megumi Ishida Tedesco, Centro Interdisciplinar de Estudos em Transportes, Universidade de Brasília, Brasília, DF, Brasil. (e-mail: g.tedesco@yahoo.com.br).

${ }^{3}$ Thais Maria de Andrade Villela, Centro Interdisciplinar de Estudos em Transportes, Universidade de Brasília, Brasília, DF, Brasil. (e-mail: tmavillela@yahoo.com.br).

${ }^{4}$ Sérgio Ronaldo Granemann, Centro Interdisciplinar de Estudos em Transportes, Universidade de Brasília, Brasília, DF, Brasil. (e-mail: sergiog@unb.br).
}

Manuscrito recebido em 12/1/2012 e aprovado para publicação em 5/5/2012. Este artigo é parte de TRANSPORTES v. 20, n. 1, 2012. ISSN: 2237-1346 (online).
- Maior conhecimento da oferta de transporte de cargas;

- Análise da distribuição espacial e da idade da frota;

- Fiscalização do exercício da atividade;

- Regularização da atividade de transportador (habilitação); e

- Ordenamento e disciplina do mercado e estabelecimento de parâmetros para a entrada no mercado de transporte rodoviário de cargas (para inibir atividades irregulares ou transportadores não qualificados).

Por meio da Resolução no 437 (ANTT, 2004), em cumprimento ao determinado pela Lei $\mathrm{n}^{\circ}$. 10.233 (Brasil, 2001) em seus artigos 14-A e 26, a ANTT instituiu a obrigatoriedade do registro a autônomos (mais conhecidos como caminhoneiros), empresas e cooperativas que prestam serviços de transportes de cargas mediante remuneração. Segundo a Agência, em 2010, o RNTRC contava com 569.923 transportadores cadastrados, sendo 86.411 empresas, 255 cooperativas e 483.257 autônomos.

Foi a partir da publicação da Lei $n^{\circ}$. 11.442 (BRASIL, 2007) e da Resolução no. 3.056 (ANTT, 2009c), que o RNTRC deixou de ser apenas um cadastro e passou a ter caráter de habilitação obrigatória para o desempenho da atividade de transportador rodoviário de cargas mediante remuneração. Nesse novo contexto jurídico-institucional do setor, constatou-se a necessidade de aprimoramento dos mecanismos de expedição do RNTRC.

É esperado que as novas restrições impostas aos transportadores gerem impacto direto no mercado de TRC no Brasil. O presente trabalho procura identificar e analisar as principais alterações no registro dos transportadores em função das novas exigências da legislação. Posteriormente, os impactos no mercado poderão ser acompanhados conforme as mudanças no perfil dos transportadores cadastra- 
dos no RNTRC.

\section{HISTÓRICO DA REGULAMENTAÇÃO}

O Transporte Rodoviário de Cargas (TRC) há muito se apresenta como o principal meio de deslocamento de cargas no território brasileiro. Desde o fim da $2^{\mathrm{a}}$ Guerra Mundial, robustos investimentos foram realizados neste modo de transporte, começando pela Lei Joppert (Decreto-Lei $\mathrm{n}^{\circ}$. $8.463 / 45$ ) e passando mais tarde pelo governo do presidente Juscelino Kubitschek (Gomes, 2006).

Somente em 1974, no governo do Presidente Geisel, os investimentos no transporte rodoviário foram reduzidos, quando o governo priorizou a Ferrovia do Aço (Gomes, 2006). Nesta época, no entanto, a matriz de transporte já estava desequilibrada, com grande favorecimento ao modo de transporte rodoviário em detrimento dos demais. Este desequilíbrio perdura até os dias atuais.

Em 1980, dado o contexto de acentuado desenvolvimento do TRC no Brasil, foi promulgada a Lei 6.813 (BRASIL, 1980), que estabelecia, entre outras coisas, que a exploração do TRC deveria ser atividade privativa de transportadores autônomos brasileiros. Posteriormente, em 1983, foi criado o Registro Nacional de Transportes Rodoviários de Bens (RTB) pela Lei 7.092 (BRASIL, 1983), que também fixava algumas condições para o exercício da atividade de TRC. Com quotas limitadas à quantidade de registros anuais de transportadores, o RTB foi destinado à inscrição e ao cadastro daqueles que exerciam a atividade de transporte de bens (próprios ou de terceiros) com fins econômicos ou comerciais, por via pública ou rodovia, tendo efeito de autorização legal para o transporte.

Considerada incompatível com a Constituição de 1988, a Lei 7.092/83 (BRASIL, 1983) foi revogada e, desde então, não houve mais qualquer disciplinamento ou regra para o acesso à atividade de transportador rodoviário de cargas no Brasil. Somente em 2001, com a criação da ANTT pela Lei $\mathrm{n}^{\circ} 10.233$ (BRASIL, 2001), a regulação do mercado de TRC voltou a ser considerada.

Fundamentadas na realidade e nas necessidades de regulação do setor, algumas leis e resoluções foram publicadas, iniciando em 2001 e continuando até a recente Resolução $\mathrm{n}^{\mathrm{o}}$. 3.056/09, da ANTT. Cabe citar que uma das atribuições da ANTT é o estabelecimento de marcos regulatórios e desenvolvimento instrumentos para a regulação do setor de transporte rodoviário de cargas. A ANTT tem também a incumbência de promover estudos relativos à frota e aos transportadores constituídos, sendo responsável por organizar e manter o RNTRC.

Este registro e a regulamentação do TRC só vieram a ocorrer efetivamente com a publicação da Resolução $n^{\circ} .437$ (ANTT, 2004), que trata do exercício da atividade de transporte rodoviário de cargas, por conta de terceiros e mediante remuneração, não incluindo, por exemplo, o transporte de cargas próprias. Tal resolução tornou obrigatório o registro do transportador junto à ANTT, o qual é válido por quatro anos. Não há cobrança de taxas ou emolumentos, mas passou a ser necessário o cadastramento de toda a frota sob sua propriedade para poder realizar o transporte.

Inicialmente, para que o transportador pudesse realizar suas atividades, o RNTRC exigia dados gerais do transportador e um cadastro legal que especificasse, entre outros, as quantidades e tipos de veículos, a área de armazenagem e a principal área de atuação.

Em 2006, a ANTT publicou a Resolução no. 1.737 (ANTT, 2006), suprindo algumas omissões da resolução anterior, como era o caso da capacidade de carga dos veículos, definindo a capacidade de carga útil mínima maior ou igual a 1,5 toneladas (Capacidade de Carga Útil - CCU $\geq$ $1,5 \mathrm{t}$ ), para se caracterizar um TRC. Por meio desta resolução a ANTT restringiu também o registro de empresas que não apresentavam como uma de suas atividades o transporte rodoviário de cargas, de acordo com a legislação vigente. Menos de um mês depois de publicada a Resolução $n^{\circ}$. 1.737/06 foi sancionada a Lei $n^{\circ} .11 .442$ (Brasil, 2007), que dispõe sobre o transporte rodoviário de cargas por conta de terceiros e mediante remuneração, trazendo nova regulamentação ao setor.

Até o dia 8 de janeiro de 2007, quando ocorreu a publicação da Lei $\mathrm{n}^{\circ}$. 11.442/07, não existia legislação específica que definisse exigências para a entrada e a saída no mercado de TRC. Como declara a própria ANTT (2009b), a regulação por ela exercida, por meio das resoluções, visava a fins precipuamente estatísticos para o estudo do mercado. Não tinha, portanto, fins de controle ou de fiscalização; apenas de acompanhamento. Entretanto, a Lei no ${ }^{\circ} 11.442$ (Brasil, 2007) consolidou as regulamentações já publicadas por meio das resoluções da ANTT, como a inscrição prévia do transportador e sua regularidade cadastral, além de apresentar dois novos requisitos para o exercício da atividade de TRC: a comprovação de experiência e a responsabilidade das partes na execução do transporte.

Ciente da relevância do TRC para a economia, o governo federal tem demonstrado grande interesse no desenvolvimento de um setor de transporte estável e eficiente, a fim de sustentar o crescimento econômico nacional. Para a viabilização deste desenvolvimento controlado, priorizando a solução dos problemas mais relevantes, faz-se necessário, contudo, possuir um conhecimento mais aprofundado do setor, já que, como afirmam Bowersox e Closs (2001), para compreender as tomadas de decisão em transporte é importante entender o ambiente do transporte.

Até há pouco tempo, as informações a respeito do setor eram escassas e essa falta de conhecimento mais detalhado era atribuída ao fato de não existirem mecanismos que possibilitassem, ao Governo e aos órgãos de fiscalização, o devido acompanhamento da sua evolução (Roviriego et. al, 2006). Atualmente, ainda há uma carência de informações sobre o setor, principalmente com relação à carga transportada. Mas os dados constantes no RNTRC já permitem o maior conhecimento sobre a oferta de TRC no Brasil, ou seja, atualmente é possível identificar algumas características dos transportadores rodoviários de cargas. Com as novas restrições impostas por meio da Lei 11.442/07 e Resolução ANTT no. 3.056/09, são esperadas mais mudanças no perfil desses transportadores. A seguir, serão descritas as principais restrições que podem influenciar o mercado de TRC no Brasil.

\section{A LEGISLAÇÃO ATUAL DO TRANSPORTE RODOVIÁRIO REMUNERADO DE CARGAS}

Conforme comentado anteriormente, a Lei no. 11.442 (Brasil, 2007) consolidou as ações regulatórias já praticadas pela ANTT e regulamentou o TRC como atividade de natureza comercial, em regime de livre concorrência, regulado 
pela ANTT. Com a regulação do TRC, o RNTRC passou de um simples registro, com fins de monitoramento estatístico, para um instrumento que permite a habilitação do transportador.

A partir da vigência da Lei $n^{\circ}$. 11.442/07, segundo a ANTT (2009b), o RNTRC passou a servir como instrumento para garantir a profissionalização dos transportadores e a qualidade dos serviços. A profissionalização é alcançada pelas restrições de experiência e regularização dos responsáveis pelo transporte, enquanto a melhoria na qualidade dos serviços está baseada na definição clara das atribuições de cada parte, suas obrigações e suas limitações, além de definir algumas obrigatoriedades para o transporte. Ainda que a Lei $n^{\circ}$. 11.442 (Brasil, 2007) tenha apresentado as diretrizes da proposta de habilitação do transportador no ano de 2007, as restrições, obrigações e necessidades para sua regulamentação foram esclarecidas apenas em 2008 pela ANTT, através da Resolução $n^{\circ}$. 2.550/08, que foi substituída posteriormente pela Resolução $\mathrm{n}^{\circ}$. 3.056/09. A seguir são comentadas as principais alterações trazidas por essas resoluções.

\subsection{Atividade principal - Transporte rodoviário de cargas}

A Resolução no. 3056 (ANTT, 2009c) estabelece que somente as empresas que têm o transporte rodoviário de cargas como atividade principal podem realizar seu registro no RNTRC, sendo este exigido apenas para a matriz e não para as filiais. Esta restrição tende a reduzir significativamente o conjunto de empresas prestadoras de serviços de transporte num primeiro momento, uma vez que não basta realizar o transporte; o transporte rodoviário de cargas deve ser sua atividade principal.

A exigência da obrigatoriedade do RNTRC tem facilitado a execução de pesquisas, estudos e análises que ajudam a entender melhor a atividade de transporte rodoviário de cargas no Brasil e a sugerir medidas que visem seu aperfeiçoamento. Uma dessas análises, por exemplo, realizada pelo Ceftru (2006), mostrou que aproximadamente $80 \%$ das empresas com mais de 80 veículos apresentam como atividade principal o transporte rodoviário de cargas. Em outras palavras, aproximadamente $20 \%$ das empresas com mais de 80 veículos estariam em desacordo com a Resolução e, portanto, não poderiam cadastrar-se no RNTRC. É importante ressaltar que as empresas com mais de 80 veículos representam apenas $0,56 \%$ do total de transportadores cadastradas no RNTRC, mas possuem $23,27 \%$ do total de veículos cadastrados. Como já citado anteriormente, vale ressaltar que toda a disposição da Lei $n^{\circ} .11 .442$ (Brasil, 2007) trata única e exclusivamente do TRC por conta de terceiros e mediante remuneração, não contemplando, entre outras, as operações de transporte dos produtos das empresas quando realizado por meios próprios.

\subsection{Responsabilidade técnica}

Uma das exigências que mais criou controvérsias entre as empresas que operam no TRC foi a exigência da figura do responsável técnico da empresa (RT), exigida pela resolução $\mathrm{n}^{\mathrm{o}} 3.056$ (ANTT, 2009c), que regulamentou uma parte da lei $n^{\circ} 11.442$ (BRASIL, 2007) que versava sobre esse assunto. Tal exigência visava proporcionar maior segurança nos serviços prestados pelas empresas que atuam no setor. A citada resolução estabelece que o RT deve ter experiência na área (mínimo de 3 anos) ou então fazer um curso es- pecífico. Quanto aos transportadores autônomos de carga (TAC), é exigido do próprio transportador a experiência mínima de 3 anos ou o curso específico.

Segundo a lei que criou a figura do RT, este profissional está incumbido de responder pela adequação e pela manutenção de veículos, equipamentos e instalações da empresa/cooperativa, bem como pela qualificação e pelo treinamento profissional de seus funcionários de operação e dos prestadores de serviço.

No âmbito da empresa ou cooperativa, o RT é um dos principais responsáveis pela parte operacional do serviço de transporte, sendo o único submetido à exigência de experiência prévia (ou curso). Além disso, a empresa ou cooperativa que excluir o registro do seu responsável técnico terá o RNTRC suspenso.

A Resolução $n^{\circ}$. 3.056, da ANTT (2009c), apresenta, também, o currículo mínimo obrigatório (Tabela 1) elaborado por especialistas da área e da Agência, para a validação do curso e indica os critérios necessários para atendimento dos 3 anos de experiência exigidos tanto para os Responsáveis Técnicos (RT) quanto para os Transportadores Autônomos (TAC).

$\mathrm{O}$ curso propõe um módulo inicial contextualizando o TRC em seus aspectos conceituais, sociais, espaciais e econômicos, apresentando sua importância no Brasil. Este módulo ainda discorre sobre os tipos de veículos e cargas e apresenta noções de atividades de logística e transporte de cargas.

O segundo módulo apresenta a legislação pertinente ao TRC, incluindo conceitos de responsabilidade civil, documentação e tributação. Na sequência, apresenta-se um terceiro módulo voltado para a operação do transporte de cargas: tecnologias embarcadas, operação em terminais, movimentação, acondicionamento. $\mathrm{O}$ último módulo traz a gestão e qualidade na prestação dos serviços de transporte de carga, incluindo aspectos relacionados ao planejamento e à gestão do transporte.

A resolução que propôs e apresentou a grade curricular mínima obrigatória também definiu os requisitos para a aprovação no curso específico, sendo que TAC e RT devem, no mínimo, apresentar setenta e cinco por cento de presença e obter nota superior a setenta por cento da nota máxima possível.

Quanto à experiência prévia do transportador autônomo, a Resolução $n^{\circ}$. 3.056 (ANTT, 2009c) define como suficiente:

- Ter atuado como responsável técnico em empresa de TRC;

- Quitação da contribuição previdenciária à Previdência Social, como contribuinte individual, na categoria de motorista profissional; e

- Ter desenvolvido atividades de técnico em transporte rodoviário, logística em transporte multimodal, gerente de operações, diretor de operações ou motorista profissional de veículo rodoviário de cargas, baseado na Classificação Brasileira de Ocupações do Ministério do Trabalho e Emprego (CBO/MTE).

Para comprovação de realização dessas atividades é necessária a apresentação de documentos pertinentes para cada caso. Vale ressaltar que a comprovação de experiência por atuação como RT só será válida para os próximos registros e os recadastramentos periódicos, uma vez que é uma 
Tabela 1. Estrutura curricular dos cursos para TAC e RT

\begin{tabular}{|c|c|}
\hline \multicolumn{2}{|c|}{ Estrutura curricular dos cursos para TAC $(84 \mathrm{~h} / a)$ e RT $(125 \mathrm{~h} / \mathrm{a})$} \\
\hline Conhecimento específico - TAC & Conhecimento específico $-R T$ \\
\hline \multicolumn{2}{|l|}{ Conhecimentos básicos do setor de transporte de cargas } \\
\hline Carga horária: $20 \mathrm{~h} / a$ & Carga horária: 25 h/a \\
\hline O transporte rodoviário de cargas & O transporte rodoviário de cargas \\
\hline Tipos de cargas e veículos & Tipos de cargas e veículos \\
\hline Noções de atividades do transporte de cargas & Noções e atividades da logística e do transporte de cargas \\
\hline \multicolumn{2}{|l|}{ Módulo II } \\
\hline \multicolumn{2}{|l|}{ Legislação específica do transporte de cargas } \\
\hline Carga horária: $12 \mathrm{~h} / \mathrm{a}$ & Carga horária: 15 h/a \\
\hline Legislação e documentação do transporte de cargas & Legislação e documentação do transporte de cargas \\
\hline \multicolumn{2}{|l|}{ Módulo III } \\
\hline Carga horária: $42 h / a$ & Carga horária: $60 \mathrm{~h} / \mathrm{a}$ \\
\hline Saúde, meio ambiente e segurança do trabalho & Saúde, meio ambiente e segurança do trabalho \\
\hline Tecnologia embarcada e equipamentos de controle operacional & Tecnologia embarcada e equipamentos de controle operacional \\
\hline Condução econômica e defensiva & Operação em terminais e armazéns de mercadorias \\
\hline Noções de operação em terminais e armazéns de mercadorias & Movimentação, acondicionamento e embalagem \\
\hline Noções de movimentação, acondicionamento e embalagem & Administração da frota e roteirização \\
\hline Tarifas e custos de transportes & \\
\hline \multicolumn{2}{|l|}{ Módulo IV } \\
\hline \multicolumn{2}{|c|}{ Gestão e qualidade na prestação dos serviços de transporte de cargas } \\
\hline Carga horária: $10 \mathrm{~h} / \mathrm{a}$ & Carga horária: 25 h/a \\
\hline Qualidade na prestação dos serviços de transporte de cargas & $\begin{array}{l}\text { Qualidade na prestação de serviços de transporte de cargas } \\
\text { Noções de planejamento e gestão do transporte }\end{array}$ \\
\hline
\end{tabular}

função formal nova.

O Responsável Técnico também precisa comprovar a experiência para executar a função no transporte de carga. A experiência pode ser comprovada por:

- Ter exercido a atividade de transportador autônomo de cargas;

- Ser ou ter sido sócio ou diretor de empresa de transporte rodoviário de cargas; e

- Ter desenvolvido atividades de técnico em transporte rodoviário, logística em transporte multimodal de cargas, gerente de operações ou diretor de operações de transporte de cargas, com base na CBO/TEM.

Da mesma maneira que ocorre com os autônomos, a comprovação da experiência para o RT é feita mediante apresentação da documentação pertinente.

É importante observar que, a partir da nova legislação, a habilitação de novos transportadores tornou-se mais restritiva; seja pela comprovação de experiência prévia ou pelo curso específico, espera-se trazer mais segurança no TRC, contando com a responsabilidade e a capacitação dos transportadores.

\subsection{Idoneidade}

A Lei $n^{\circ} .11 .442$ (BRASIL, 2007) exigia a idoneidade dos sócios e do responsável técnico sem definir, explicar ou mesmo mencionar a forma de comprovação e o intuito desta condição. Na Resolução $\mathrm{n}^{\circ} .3 .056$ (ANTT, 2009c), a ANTT passou também a exigir uma declaração da empresa quanto à idoneidade de seus diretores e responsáveis legais. Com relação à idoneidade do Responsável Técnico, o artigo 18 da Resolução n”. 3.056 (ANTT, 2009c) cita que "será inicialmente demonstrada mediante declaração da ETC [Empresa de Transporte Rodoviário de Cargas] requerente, sobre a capacidade do indicado para o exercício da atividade".

Seguindo as mesmas diretrizes impostas às empresas, no registro de cooperativas é exigida a idoneidade dos responsáveis legais, diretores e de seus cooperados, nos mesmos moldes das demais declarações de idoneidade, além da idoneidade do responsável técnico, conforme o Artigo 18, citado anteriormente.

Por se tratar de uma declaração da própria empresa, sem necessidade de comprovação e sem validade prevista, a idoneidade transfere ao transportador a responsabilidade pelas informações prestadas; contudo, não limita sua atuação. Com esta declaração, a ANTT busca respaldar-se para que possa atuar de acordo com a legislação vigente nos casos em que for comprovada a inidoneidade do transportador.

\subsection{Regularidade fiscal e cadastral}

Desde a publicação da Resolução nº 437 (ANTT, 2004), a ANTT exige regularidade cadastral dos transportadores para realizar os serviços de transporte. Nesta resolução era exigido da empresa o registro na Junta Comercial, inscrição estadual e alvará de funcionamento e, do transportador autônomo, a inscrição junto à Receita Federal e à Previdência Social. A partir da Resolução no 2.550 (ANTT, 2008), exige-se, adicionalmente, a comprovação de pagamento da contribuição sindical e a Certidão Negativa de Falência.

Somente após a publicação da Resolução $\mathrm{n}^{\circ}$. 3.056 (ANTT, 2009c), a ANTT começou a exigir a regularidade fiscal do transportador, além da regularidade cadastral como prestador de serviços. Esta resolução exige que o transportador esteja regular no ato do cadastramento e enquanto estiver registrado. Essa pequena diferença no texto da Resolução traz grandes diferenças para a regulação do TRC.

Com a publicação da Resolução $\mathrm{n}^{\circ}$. 3.056 (ANTT, 
2009c), para registro no RNTRC o transportador autônomo precisa comprovar não somente que está inscrito, mas que não apresenta pendência anterior junto à Receita Federal, à Previdência Social e aos sindicatos; as empresas transportadoras precisam ainda comprovar regularidade junto à Procuradoria Geral da Fazenda Nacional e demonstrar que todos os sócios, os diretores e o responsável técnico estão regulares perante a Receita Federal.

Para ilustrar essas mudanças, podem ser consideradas as alterações relativas ao CPF e ao CNPJ. Antes da publicação da Resolução $n^{\circ}$. 3.056/09, o transportador precisava apenas possuir CPF ou CNPJ. Atualmente, é exigido também que esses documentos estejam com situação ativa e válida permanentemente. Como o registro agora é feito por formulário eletrônico, via internet, a ANTT pode invalidar o registro automaticamente, caso o transportador apresente alguma irregularidade. Para isto, a ANTT necessita realizar convênios com os órgãos responsáveis para a consulta automática às bases de dados.

\subsection{Outras mudanças}

A Resolução $n^{\circ} .3 .056$ (ANTT, 2009c) trouxe ainda algumas mudanças em relação à regulamentação existente. Até a publicação desta resolução, as cooperativas de transporte poderiam registrar veículos somente em nome de seus cooperados. A partir da Resolução n ${ }^{\circ}$. 3.056/09 foi permitido também o registro de veículos em nome da cooperativa.

A nova resolução restringe ainda o registro de veículos da categoria "particular", "passageiros" e de veículos na categoria "aluguel" com Capacidade de Carga Útil (CCU) in-

Tabela 2. Dados exigidos dos transportadores autônomos no RNTRC

\begin{tabular}{l}
\hline Dados de Transportadores Autônomos \\
\hline CPF ativo \\
Nome e Identidade \\
Endereço completo \\
Regularidade junto ao INSS \\
Contribuição sindical \\
Comprovação de experiência do transportador Autônomo \\
Dados da frota \\
Fonte: Resolução no. 3.056, daANTT (2009c)
\end{tabular}

Tabela 3. Dados exigidos das empresas e cooperativas no RNTRC

\begin{tabular}{l}
\hline Dados de Empresas e Cooperativas \\
\hline CNPJ ativo \\
Razão social \\
Código CNAE \\
Endereço completo da matriz \\
Contribuição sindical \\
CPF do responsável legal \\
Regularidade fiscal junto à Receita Federal \\
Regularidade fiscal junto à Procuradoria Geral da \\
Fazenda Nacional (PGFN) \\
Regularidade junto ao FGTS \\
Regularidade fiscal junto ao INSS \\
Identidade do Responsável Técnico \\
CPF do Responsável Técnico \\
Comprovação de experiência do Responsável Técnico \\
CPF dos sócios / cooperados \\
CPF do diretor (se houver) \\
Dados da frota \\
\hline Fonte: Resoluçãono. 3.056, daANTr(2009c)
\end{tabular}

ferior a 500 quilos, ou então dos tipos "tração de rodas", "tração de esteiras" e "trator misto", conforme classificação do Código de Trânsito Brasileiro (CTB). Nesses casos é vedada a inclusão ou manutenção no RNTRC.

Por fim, na Lei $\mathrm{n}^{\circ}$. $11.442 / 07$ e na Resolução $\mathrm{n}^{\circ}$. 3.056/09 não é mais necessário que o transportador possua ao menos um veículo de sua propriedade. Agora o transportador pode exercer as atividades de transporte rodoviário remunerado de cargas, mesmo que todos os seus veículos sejam arrendados. Neste caso, a exigência atual está mais focada na "posse" do veículo do que na "propriedade", sendo imprescindível que o transportador tenha pelo menos um veículo com CCU igual ou superior a 500 quilos em sua posse.

As Tabelas 2 e 3 trazem a lista dos dados requeridos dos transportadores pela atual legislação.

\section{CONCLUSÕES}

A nova legislação para o Transporte Rodoviário de Cargas modificou a estrutura do setor. Mudanças no mercado de TRC, em função de alterações no tipo e na quantidade de veículos registrados, das alterações no limite de CCU, e em relação às categorias de transportadores registrados no RNTRC, já são observadas nas estatísticas. Note-se, por exemplo, que o quantitativo de transportadores registrados em 2006 era de 770.660 transportadores, enquanto que em 2011, segundo a ANTT, este número caiu para cerca de 660.000 transportadores, entre autônomos, empresas e cooperativas. Isso é reflexo das exigências introduzidas pela legislação atual do setor.

Não se pode ainda quantificar o quanto cada exigência da legislação influenciou, em termos quantitativos, a redução dos operadores habilitados no RNTRC, no período entre 2006 e 2011. A evolução do registro e as novas análises feitas a partir dos dados alimentados pelos transportadores é que poderão mensurar essas influências com mais precisão.

É fato, porém, que as alterações promovidas pela legislação contribuem para qualificar melhor os transportadores rodoviários remunerados de carga, na medida em que exigem experiência no ramo ou capacitação dos transportadores para o exercício da atividade. Também dão ênfase à concessão da habilitação para aqueles transportadores que estejam em dia com suas obrigações fiscais e tributárias.

Por outro lado, o RNTRC disponibiliza dados e informações sobre o transporte rodoviário remunerado de cargas que não eram de conhecimento público no País. Isso permite o desenvolvimento de políticas públicas mais eficientes e adequadas por parte dos órgãos de planejamento, de monitoramento e de controle.

Do ponto de vista do transportador, várias consequências da introdução da nova legislação podem ser observadas. Entre elas cabe destacar:

- A regularização do exercício da atividade por meio da habilitação formal;

- O disciplinamento do mercado para consolidar o uso do conhecimento de transporte e definir a responsabilidade de cada parte;

- A obrigatoriedade do registro para ser habilitado a oferecer serviços de transporte remunerado de cargas; e

- A identificação de parâmetros econômicos, jurídicos 
e legais para regular o mercado, inibindo a participação de transportadores que não estejam minimamente qualificados para o exercício da atividade.

O RNTRC propicia também um maior volume de informações do setor de transporte rodoviário remunerado de cargas aos estudiosos do setor. Isso alimenta pesquisas que tratam da estrutura econômica do mercado, do grau de concentração do setor, dos tipos de carga transportados, da natureza e características dos veículos utilizados, da idade da frota, entre outros estudos que ajudam a conhecer melhor o funcionamento e a estrutura desse setor.

\section{REFERÊNCIAS BIBLIOGRÁFICAS}

ANTT (2002) Resolução nº. 01. Aprova o Regimento Interno e a Estrutura Organizacional da Agência Nacional de Transportes Terrestres ANTT. Agência Nacional de Transportes Terrestres. Diário Oficial da União, 20 março 2002.

ANTT (2004) Resolução nº. 437. Institui o Registro Nacional de Transportadores Rodoviários de Carga - RNTRC. Agência Nacional de Transportes Terrestres. Diário Oficial da União, 16 março 2004.

ANTT (2006) Resolução n ${ }^{\circ}$. 1.737. Estabelece procedimentos de registro e fiscalização, institui infrações e sanções referentes ao Registro Nacional de Transportadores Rodoviários de Carga - RNTRC, e dá outras providências. Agência Nacional de Transportes Terrestres. Diário Oficial da União, 04 dezembro 2006.

ANTT (2008) Resolução $\mathrm{n}^{\circ}$. 2.550. Dispõe sobre o exercício da atividade de transporte rodoviário de carga por conta de terceiros e mediante remuneração e estabelece procedimentos para inscrição no Registro Nacional de Transportadores Rodoviários de Carga RNTRC, e dá outras providências. Agência Nacional de Transportes Terrestres. Diário Oficial da União, 27 março 2008.

ANTT (2009a) Resolução nº. 3.000. Aprova o Regimento Interno e a Estrutura Organizacional da Agência Nacional de Transportes Terrestres - ANTT. Agência Nacional de Transportes Terrestres. Diário Oficial da União, 18 fevereiro 2009.

ANTT (2009b) Agência Nacional de Transportes Terrestres. Disponível em: <http://www.antt.gov.br> (Acesso em 19/06/2009).

ANTT (2009c) Resolução nº. 3.056. Dispõe sobre o exercício da atividade de transporte rodoviário de cargas por conta de terceiros e mediante remuneração, estabelece procedimentos para inscrição e manutenção no Registro Nacional de Transportadores Rodoviários de Cargas - RNTRC e dá outras providências. Agência Nacional de Transportes Terrestres. Diário Oficial da União, 13 março 2009.

Bowersox, D. J. e Closs, D. J. (2001) Logística Empresarial: O Processo de Integração da Cadeia de Suprimento. Ed. Atlas. São Paulo, SP.

Brasil (1980) Lei $\mathrm{n}^{\circ}$. 6.813. Dispõe sobre o transporte rodoviário de cargas, e dá outras providências. Diário Oficial da União, 11 agosto 1980.

Brasil (1983) Lei n.7.092. Cria o Registro Nacional de Transportes Rodoviários de Bens, fixa condições para o exercício da atividade e dá outras providências. Diário Oficial da União, Brasília, 20 abril 1983.

Brasil (1984) Lei $n^{\circ}$. 7.290. Define a atividade do transportador rodoviário autônomo de bens e dá outras providências. Diário Oficial da União, 20 dezembro 1984.

Brasil (2001) Lei nº 10.233. Dispõe sobre a Reestruturação dos Transportes Aquaviário e Terrestre, cria o Conselho Nacional de Integração de Políticas de Transporte, a Agência Nacional de Transportes Terrestres, a Agência Nacional de Transportes Aquaviários e o Departamento Nacional de Infraestrutura de Transportes, e dá Outras Providências. Diário Oficial da União, 06 junho 2001.

Brasil (2007) Lei nº 11.442. Dispõe sobre o Transporte Rodoviário de Cargas por Conta de Terceiros e Mediante Remuneração e Revoga a Lei $n^{\circ}$. 6.813, de 10 de julho de 1980. Diário Oficial da União, 08 agosto 2007.

Ceftru (2006) Centro de Formação de Recursos Humanos em Transportes. Relatório de Análise do Transporte Rodoviário de Carga: Um Estudo Baseado no RNTRC. Volume I.

CNT (2011) Boletim Estatístico. Confederação Nacional do Transportes, Brasília, DF, maio de 2011.
Gomes, R. A. (2006) Transporte Rodoviário de Cargas e o Desenvolvimento Econômico no Brasil: Uma análise descritiva. Dissertação (Mestrado). Departamento de Engenharia Civil e Ambiental, Universidade de Brasília. Brasília.

Roviriego, L. F. V.; L. G. P. L. Carneiro; M. F. B. Alves; D. R. Aldigueri; E. J. C. Costa e Y. Yamashita (2006) Determinação da Capacidade de Carregamento de Veículos de Transporte Rodoviário de Carga: uma Proposta Baseada no RNTRC. XX Congresso Nacional de Ensino e Pesquisa em Transportes - ANPET, Anais..., Brasília, DF. 